\title{
La fotografía como documento de análisis, cuerpo y medicina: teoría, método y crítica - la experiencia del Museo Nacional de Medicina Enrique Laval
}

\author{
Photography as analysis document, body and medicine: theory, \\ method and criticism - the experience of Museo Nacional de \\ Medicina Enrique Laval
}

César Leyton Robinson cleytonr@med.uchile.cl

Andrés Díaz Caballero andiaz@med.uchile.cl

Museo Nacional de Medicina Enrique Laval Facultad de Medicina/ Universidad de Chile Biblioteca Central $5^{\circ}$ piso Av. Independencia 1027 Comuna de Independencia Santiago - Chile
ROBINSON, César Leyton; CABALLERO, Andrés Díaz. La fotografía como documento de análisis, cuerpo y medicina: teoría, método y crítica - la experiencia del Museo Nacional de Medicina Enrique Laval. Histórica, Ciências, Saúde-Manguinhos, Rio de Janeiro, v.14, n.3, p.991-1012, jul.-set. 2007.

Este artículo es una reflexión metodológica experimental sobre la utilización de la imagen médica como documento importante para la construcción de la historia de la medicina. Un método basado en directrices o temáticas de análisis que incluyen diferentes 'miradas' al documento. Desde las teorías estéticas, técnicas, sociales, políticas, hasta llegar a la reflexión médicohistórica. Además se incluyen algunos ejercicios que enriquecen la propuesta al lector: redescubrir los mundos sociales que esconden estos archivos fotográficos médicos para tener accesos teóricos nuevos a lo que es el montaje histórico de la ciencia médica.

PALABRAS CLAVE: medicina; fotografía; archivo; método; sociedad.

ROBINSON, César Leyton; CABALLERO, Andrés Díaz. Photography as analysis document, body and medicine: theory, method and criticism - the experience of Museo Nacional de Medicina Enrique Laval. Histórica, Ciências, Saúde-Manguinhos, Rio de Janeiro, v.14, n.3, p.991-1012, July-Sept. 2007.

This article is an experimental methodological reflection on the use of medical images as useful documents for constructing the history of medicine. A method is used that is based on guidelines or analysis topics that include different ways of viewing documents, from aesthetic, technical, social and political theories to historical and medical thinking. Some exercises are also included that enhance the proposal for the reader: rediscovering the worlds in society that harbor these medical photographical archives to obtain a new theoretical approach to the construction of the history of medical science.

KEYWORDS: medicine; photography; archive; method; society. 
E ste ensayo aspira a develar uno de los discursos visuales que existen sobre el cuerpo humano elaborado a partir del desarrollo de las doctrinas médicas que se han construido a lo largo de la historia de la medicina.

Durante siglos, el discurso científico-médico elaboró registros gráficos como litografías, agua fuertes, etc. que comienzan a desarrollarse en la Europa del siglo XV y fotografías a mediados del siglo XIX, con el descubrimiento de ésta en 1839 (Nungesser, 2004, p.141). Unas de las funciones que cumplieron dentro del conocimiento fue describir al cuerpo, tanto sano como enfermo, con un espíritu taxonómico, donde la mirada científica lo desnudaba para su quehacer cotidiano.

El aparato científico-médico clasificó estados, condiciones y grupos humanos con el fin de reunir información sobre el cuerpo a examinar. Sin embargo, desde sus orígenes se revela que el discurso científico-médico evoluciona hacia una mirada normativa, donde la enfermedad se transforma en una condición de impureza y desviación, solo propia de los grupos sociales vulnerables. En cambio, el cuerpo sano era una condición propia de la 'normalidad', no solamente física, sino social.

Al igual que en la polis, en la naturaleza no existiría ningún poder que prevaleciera sobre otro, pues su consecuencia sería la ruina del Cosmos; se trataría de un equilibrio de poderes desiguales, dinámico, conflictivo, pero sujeto a un orden y una justicia. Desde esta concepción del mundo, se entendió el cuerpo humano y su salud. El equilibrio de las fuerzas, dynámeys constituirían la salud, mientras que el predominio, la monarkhía de algunas de ellas era causa de enfermedad. (Ruiz, 1993, p.52-53)

Este mismo artefacto visual, ya sea un grabado o una fotografía, al ser revisado desde la contemporaneidad de la historia de la medicina, sufre una mutación que nos revela nuevas y distintas interpretaciones que se alejan de la mirada médica original. Las técnicas, los espacios, los rostros, los instrumentos, permiten dimensionar no solo la fisonomía del pasado médico, sino también la realidad de un pasado social.

Posiblemente la diferencia que se destacaría en un estudio sobre la importancia de la fotografía en este momento histórico debería centrarse en la fuerza visual de su existencia y en una fuerza similar aplicada al análisis del individuo y de la sociedad en la que vive. Un análisis a veces abstracto y teórico, otras veces directo y descarnado, en ocasiones lírico y en otros momentos épico. (Olivares, dic. 1996, p.31)

¿Qué se entiende por una imagen médica? Es aquella que produce una transformación en la condición del sujeto a representar, donde 
el estado del sujeto, luego de una clasificación muta al estado de 'objeto'. En este estado, solo es de interés percibir la condición de paciente como estado único, excluyendo cualquier otra condición o realidad del sujeto. Es decir, se percibe al individuo como un espécimen bajo un microscopio, del mismo modo que los naturalistas del siglo XIX catalogaron el mundo vegetal y animal en sus viajes. El cuerpo se convirtió en propiedad de la ciencia a partir de la industrialización de fines del siglo XVIII en una nueva condición de los procesos de colonización que se vivieron en algunos territorios.

Una mirada más pluralista de la imagen, con enfoques matizados, es decir que incluya diferentes perspectivas desde nuestra contemporaneidad, analizando diferentes niveles de la autoría de la imagen y la obviedad de su intención (registro y teoría médica), permite describir realidades encubiertas que fácilmente pasan desapercibidas y así comenzar a liberar a la imagen de los procesos de colonización que provoca y que muchas veces también acompañó a la fotografía de fines del siglo XIX (registros de etnias para museos europeos, paisajes fronterizos australes conquistados, etc.). Descolonizar la imagen fotográfica, su funcionalidad y su interpretación única, para liberarla de sus relaciones de dominio y hegemonía que la limitan o potencian como documento histórico. Una imagen que se trabaje, interrogándola, para que se confronte al retrato tradicional de la disciplina que solo busca como discurso visual o estético operar como una herramienta para disecar, para dividir un espécimen y examinar su estructura. Las imágenes no solo desnudan los diferentes estados del cuerpo o la enfermedad, sino que abren distintas perspectivas para descubrir al cuerpo social cuya imagen estaba condicionada en el discurso público- médico.

Esto nos permite abordar una realidad que se filtra, que se 'cuela' de la imagen institucional de la época. Estas imágenes que pretendían desnudar un cuerpo físico, en realidad terminan desnudando, sin querer, un cuerpo social con todas sus categorías.

La divulgación de estos estudios de la fotografía médica y del capital patrimonial del Museo Nacional de Medicina Enrique Laval es fundamental expresar en la estructura teórica de este artículo. Pero, para esto, también es necesario contextualizar nuestra institución, sus orígenes y todo el legado cultural que posee esta entidad, poniendo énfasis especialmente en su archivo fotográfico.

Actualmente el Museo forma parte de la Facultad de Medicina de la Universidad de Chile, específicamente se ubica en su Biblioteca Central. El Museo fue creado en 1955 bajo la rectoría del Servicio Nacional de Salud que era la gran institución médica estatal de la época en Chile. La idea de su construcción es del doctor Enrique Laval Manrique 1895-1970, que fue el iniciador de los estudios de la historia de la medicina en Chile y el encargado de la recopilación de las colecciones de este museo. 
El doctor Laval fue un médico historiador que por su condición de burócrata de la administración de salud conocía muy bien la estructura hospitalaria, lo que le permitió tener una visión aguda para seleccionar todo el material abandonado en las bóvedas de los antiguos establecimientos hospitalarios. Sus aportes a la historia de la medicina chilena son numerosos, las obras historiográficas más importantes de este autor son Los hospitales fundados en la colonia (1935), Historia del Hospital San Juan de Dios (1949), La botica de los jesuitas (1953), Noticias sobre los médicos en Chile en los siglos XVI, XVII, XVIII, XIX, libros que estudian los orígenes de la medicina chilena, sus establecimientos hospitalarios, la vida de los médicos de antaño y el conocimiento herbolario indígena resumido en sus estudios sobre la farmacopea de los jesuitas en tiempos de la colonia chilena. El doctor Laval, sin lugar a dudas, es una de las figuras más relevantes en la construcción de los orígenes, tanto material o intelectual, de la historia de la medicina chilena.

En cuanto al archivo fotográfico que posee el museo, las primeras instantáneas datan de 1860. Este registro en su totalidad suma unas quatro mil piezas que incluyen originales del siglo XIX en papel con negativos en vidrio y nitrato. Se destaca de igual forma, un valioso álbum de 1869-1874 de reos de la ciudad de Talca (zona central de Chile) que contiene un prontuario con mil fotografías en albúmina.

El archivo fotográfico posee las siguientes colecciones:

- Fotografías de figuras médicas (retratos, ceremonias);

- Fotografías de arquitectura hospitalaria (hospitales, facultades, servicios de salud privados y públicos, etc.);

- Fotografías de tesis médicas (oftalmología, psiquiatría, cirugía, etc.);

- Fotografías de objetos patrimoniales médicos (electroterapia, medicina colonial, anestesia, medicamentos, etc.).

Además del archivo fotográfico, el museo cuenta con una biblioteca patrimonial que posee unos dos mil volúmenes (manuscritos de instituciones de la salud, revistas médicas, tesis, etc.) y una sala de exhibición que va mostrando en forma permanente las más de 2.500 piezas que posee en su patrimonio (equipos e instrumental médico).

Este museo está afiliado a la Association Européene des Musées d'Historie des Sciences Médicales y es miembro de International Council of Museums (ICOM).

Lo fundamental es mostrar la forma de trabajo que se utiliza en nuestro museo, la forma cómo se trata la fotografía, las técnicas y teorías que la han sustentado y con esto lograr ser un referente para estudios con respecto a esta temática. 
1 Le llamamos 'ojo blindado' a la cámara fotográfica, por su forma y su fabricación. Pero también tiene que ver con la letra de una canción de rock argentino (Grupo Sumo) y una metáfora para recordar la agrupación de fotógrafos sociales chilenos, Asociación de Fotógrafos Independientes (AFI), que hacía registros de la represión política en tiempos de la dictadura militar chilena.
Nuestra propuesta se basa en los elementos teóricos que nos entregan algunos autores como Peter Burke, de oficio historiador, Susan Sontag, fotógrafa, y Pierre Bordieu, sociólogo. Además están los trabajos de algunos estetas alemanes y chilenos, sumándose nuestra experiencia documental de historiador y fotógrafo con nuestras propias técnicas adquiridas en nuestro trabajo patrimonial.

\section{La historia y el 'ojo blindado'}

La historia ha sido conservadora como disciplina para reconstruir nuestro pasado humano, sus técnicas no han sabido abordar la riqueza de la imagen fotográfica y tampoco han desarrollado técnicas para considerar a la fotografía como una fuente documental relevante (Burke, 2000, p.25).

Al analizar una fotografía como un documento histórico se propone una metodología que aniquile la visión de la fotografía como un simple decoro a un texto.

Se requiere categorizar el tipo de imagen que se observa y toda la información que se puede obtener, jerarquizando la información en diferentes niveles conceptuales. Es decir, valorar en términos epistemológicos lo estético e histórico, entendiéndolo como el lenguaje con que se constituye un documento visual, ya se trate de la iluminación o ángulo de toma, hasta las relaciones sociales, económicas e históricas que el documento encierra y que se asocian con códigos de representación (Müller, 1996, p.3).

El análisis se origina problematizando la imagen que se nos ofrece, a través de preguntas críticas que posibiliten abrir el documento en información, desde la línea editorial de su construcción (autor, técnica, institución), quiénes son los registrados o editados por la fotografía (población, objetos, paisajes, animales).

La escenografía fotográfica o montaje, donde todos los objetos componen un concepto visual, entrega un mensaje o discurso fotográfico que debemos aprender a leer. Un 'montaje' que por técnica y época, hace que la fotografía patrimonial sea un espacio inspeccionado, profundamente pensado que nos lleva a una situación de 'orden' dentro de la propia imagen y que funciona muchas veces con los mensajes de saber y norma que quieren entregar las disciplinas o instituciones. La composición escénica, tanto estética como social y política, es algo que se debe considerar en todo este registro y análisis.

En esto consiste la interrogación al documento, donde las preguntas se hagan en torno a los hechos representados para cuestionar lo que se quiere revelar. Implica desmantelar y descubrir el 'montaje' de este producto visual/industrial con que se construyó originariamente la fotografía para exponer lo oculto de ella y la totalidad de la realidad que entrega, desde su técnica que la fabricó 
hasta la disciplina que la utilizó. Hay que preguntarse: ¿Qué hay más allá de la intención del fotógrafo? ¿Es lícito poner en duda la aparente espontaneidad de una imagen para hacer visible una escenificación o un montaje institucional?

El tema del poder y sus relaciones en la imagen como lenguaje visual es fundamental para el análisis que se puede emprender. Muchas veces la visión de los investigadores puede verse frustrada o limitada por los intereses o dominio que ejerce un determinado grupo social, ya sea médico, político, eclesiástico o militar, entre otros intereses posibles. Este no es un tema contemporáneo menor ya que muchas veces los intereses económicos o figuras políticas han llevado a 'filtrar' las observaciones de los investigadores, según los intereses corporativos de empresas o gremios. Esto es lo radical y paradojal de la fotografía como documento, el registro se arrebata, incluso a la mirada del autor, para convertirse en un ente autónomo que nos entrega toda una realidad social que constituye la imagen-documento.

También es importante tener presente nuestra obsesión contemporánea crítica, donde la imagen se sitúa solo como un montaje que todo lo oculta sin reconocer la posibilidad que el flujo de la información visual muchas veces escapa al control institucional y autoral, careciendo de una intencionalidad política debido a la naturaleza del documento visual. Esto también puede ser un elemento a considerar en nuestro trabajo de investigación.

Esta conceptualización es necesaria para una reflexión teórica que nos guíe a un análisis fructífero y que nos permita desarrollar nuevos ejes y miradas en torno a la historia de la medicina. Bajo estas premisas proponemos un abordaje al concepto de imagen médica.

\section{La fotografía y la historia de la medicina}

$\mathrm{Al}$ abordar la historia de la medicina, desde el punto de vista del imaginario visual o pictórico que le rodea, encontramos referentes desde la antigüedad, tales como las pinturas de artistas medievales y renacentistas que nos permiten reconstruir el mundo antiguo de las enfermedades. Por ejemplo, obsérvese el análisis de pinturas medievales elaborado por el historiador francés George Duby (1999) en que se analiza la presencia de epidemias y muerte que saturaron a la pintura europea del medioevo, donde se ven representados los impactos de la lepra, la peste negra y el cólera: “La muerte está en todas partes, en la vida, el arte, la literatura. Pero los hombres de la época temen otra enfermedad, la lepra, que se considera propia de perversión sexual" (p.79).

Un segundo referente como fuente de estudio que continúa con este proceso de representación de los saberes médicos son los 
grabados en compendios de anatomía, enfermedades, retratos de médicos famosos, planos, etc., que por su extenso uso son la antesala de la fotografía médica y por tanto pioneras para el estudio de la iconografía médica. El grabado cumple a cabalidad su objetivo en la descripción del universo visual que requiere construir la ciencia médica. Las enfermedades, las mutaciones, los microorganismos, las anormalidades, los instrumentos están presentes tanto en litografías como agua fuertes. Por lo tanto, la fotografía debería ser un punto de continuidad en la construcción historiográfica que estos antiguos registros visuales iniciaron en la historia de la medicina. La importancia de la fotografía médica radica allí precisamente, donde otras formas de representación se debilitan. La fotografía, por su movilidad en instantaneidad, permite al operador fotográfico romper cercos sociales y espacios de privacidad que nos revelan mundos relegados a la mirada habitual que solo eran percibidos desde la marginalidad. Allí se ubican las fotografías de pacientes en fichas clínicas o en recintos hospitalarios y de salud, de médicos diagnosticando y aquellas que describen las condiciones materiales de vida de la población que eran utilizadas para hacer patente las condiciones en que se propagaban las enfermedades.

A pesar de las fotografías 'oficiales' de la medicina donde se rescata la figura de un importante médico, una ceremonia de un grupo de ellos o una aplicación de una técnica de la disciplina médica, debemos aprender a superar esta forma de 'mirada médica' institucional donde es importante que aparezcan en la exploración de los documentos otros registros, como los diferentes grupos sociales que habitaban estos espacios médicos (pacientes con su 'identidad' no arrebatada; obreros, militares, prostitutas, etc.). Estos retratos médicos institucionales también buscan construir monumentos históricos de su disciplina y es importante descubrir cuáles son las vidas que poseen estos espacios institucionales, más allá de los documentos-monumentos que muchas veces se vuelven ruinas dentro de los cambios estructurales de la historia.

En la historia de la medicina hay hechos específicos que pueden dar un inicio a la historia de la fotografía médica, hechos gráficos que formaron una relación experimento/fotografía y que nos permiten dar un origen a esta visión contemporánea de nuestros estudios. En 1853 el doctor Guillaume Benjamín Duchenne, pionero en electroterapia, realiza junto al fotógrafo A. Tournachon un registro de fotografías de expresiones del rostro para trabajos de fisonomía humana. También a mediados del siglo XIX, el doctor Hugh Welch construyó una serie de registros fotográficos referentes a enfermas mentales con el objetivo de describir la evolución de la patología mental a través del tiempo y la evolución de la terapia. En 1857 la fotografía criminalista de Alfonso Bertillón elabora una clasificación del cuerpo para elaborar propuestas teóricas en medi- 
cina legal. El registro de las distintas partes del cuerpo humano pasó a ser un registro policiaco mediante la fotografía. Por último, en 1895, Guillermo Roetngen hace el primer registro de una radiografía de máquina de rayos $\mathrm{X}$ con lo que se consolida la colonización del micro-mundo orgánico del cuerpo, iniciado por el microscopio en los siglos anteriores.

Estos hitos en la fotografía médica nos van permitiendo elaborar un referente para nuestro análisis y también registra un marco histórico que da origen a un punto de partida de nuestra reflexión teórica, que comprende la historia de la medicina y el rol de la fotografía como un factor dominante que comprueba y demuestra los grandes logros de una ciencia humana. Pero también, abarca una serie de factores que nos hace mirar lo no percibido, la obscenidad de la objetividad, observar el discurso científico en su concreta realidad social y política y como ésta influye sobre las determinaciones científicas, neutrales, apolíticas que realiza el propio científico o en este caso, el médico. Esto se relaciona con la manipulación de los hechos y el sesgo de los juicios científicos de una época histórica, su neutralidad en los contextos donde se sitúa o irradia su conocimiento. La fotografía registra el pasado y su verdad épica, pero también 'congela' los errores y prejuicios médicos de una época.

Estos archivos médicos visuales nos llevan a descripciones sociales de una pluralidad de lenguaje interesante que van desde trabajadores populares enfermos o militares convalecientes de una guerra que han sobrevivido encerrados en un psiquiátrico y registrados en una fotografía institucional. Así también podemos encontrar a un trabajador industrial, atendiéndose en el Seguro Obrero, o a un médico perteneciente a un movimiento social o político, sin que la idea original del fotógrafo o su mandante haya sido, en ningún momento, el graficar estos sujetos y sus problemáticas sociales.

En Chile hay muchos archivos fotográficos patrimoniales (por ejemplo: Archivo Patrimonial de la Compañía de Electricidad Chilectra) donde, muchas veces, se rescata la arquitectura de la institución que se quiere conmemorar o los espacios que se quieren graficar, donde los individuos se pierden en estos sitios de la historia y solo son entes iconografiados como meros entes decorativos a estos grandes espacios arquitectónicos históricos. En nuestra propia colección, muchas fotografías son retratos de médicos y de hospitales, lo que construye una visión monolítica y poco diversa de nuestros estudios. Esto no implica a que nos negamos a una lectura institucional donde estamos inmersos. El punto es que hay que conocer en profundidad la documentación y los diversos caminos por los cuales podemos llegar a la institucionalidad o a los márgenes de ella. 
Es por esto que la fotografía médica nos puede adentrar a mundos sociales aún no valorizados ya que, muchas veces, es la imagen del sujeto 'enfermo' la que termina mostrando la 'realidad social' de la propia enfermedad. Es, quizás, en estos documentos visuales donde encontramos a 'sujetos' anónimos históricos, graficados en un 'primer plano', sin filtros, con toda la imagen para ellos, sus manos, sus rostros, sus cuerpos, su contexto, desafiando incluso el origen del retrato de la fotografía universal, el cual partió con 'retratos de familias aristocráticas' donde su imagen representaba autoridad y poder social. Imagen que se venía repitiendo desde el Renacimiento, cuando los mecenas o grandes comerciantes burgueses eran retratados por los pintores para emerger como una nueva clase social dominante y donde los otros grupos sociales quedaban excluidos de estas imágenes o iconografías de poder.

La fotografía en el siglo XIX siguió con estas realidades visualessociales que van a continuar con un valor capital de la imagen, pero con otros agentes que reemplazarán a estas antiguas burguesías por otros grupos sociales que se desarrollarán con la industrialización y el conocimiento positivista académico que surge de este proceso de modernización. Estos son los científicos y sus 'retratos-monumentos' (grabados, pinturas, fotografías) que tallan sus momentos de reflexión, técnica y gloria y que monopolizan los espacios iconográficos sociales tradicionales y modernos de esta era industrial.

Fotografías convencionales:

1 Arquitectura

Escuela de Medicina, Universidad de Chile.

Año: comienzos del siglo XX, aproximadamente 1904.

Autor: desconocido

Técnica: fotografía. B/N

Archivo: Museo Enrique Laval, Colección. Fotografías de arquitectura hospitalaria y Facultad de Medicina, Universidad de Chile.

Contexto institucional: visita de autoridades; promoción a la modernización de la escuela.

2 Médico

Doctor Vicente Izquierdo, profesor de histología y anatomía microscópica (1850-1926).

Año: fines del siglo XIX.

Autor: desconocido; obtenida de un álbum familiar fotográfico (donación familiar).

Técnica: daguerrotipo.

Archivo: Museo Enrique Laval. Colección. Fotografías de figuras médicas. Facultad de Medicina, Universidad de Chile. Contexto institucional: retratos de médicos importantes de la institución universitaria-médica. 


\section{Análisis fotográfico}

Para concretar nuestro análisis, es necesario tratar de llevar a la práctica nuestras reflexiones, es decir, atrevernos a experimentar con nuestros documentos visuales y nuestra propia interpretación. Esto se debería lograr proponiendo una metodología que integre nuestras teorías a nuestra forma de ver las fotografías médicas patrimoniales. Este es un modelo flexible, ya que es importante que cada investigador construya su propio modelo, con sus propias categorías para así lograr su propia comprensión documental.

El documento fotográfico debe ser analizado o examinado desde perspectivas que logren definir toda la cantidad de información que conlleva. Este método debería partir por especificar la información que allí podemos encontrar, elaborar directrices que las podemos llamar 'ejes' por ser un pilar de base de análisis donde rota la información o categorizaciones que vinculen la naturaleza de la fotografía-medicina con algún aspecto que el autor considera relevante delimitar, como un dispositivo de análisis de su trabajo o investigación. Las categorías elegidas para nuestra interpretación son extensas, generales y buscan acercar el documento visual médico a las relaciones sociales de su entorno y al mundo cultural donde están insertas. Nosotros hemos elegido para nuestro análisis las siguientes categorías: lo médico, lo social, lo técnico, lo estético, lo político y lo institucional. Los fundamentos para nuestra selección (esto no excluye otras categorías) son los siguientes:

- La categorización social de la fotografía médica nos permite definir marcos contextuales históricos de las sociedades en que el documento se encuentra presente y logra importantes registros de sus relaciones y estructuras donde se desenvuelve la disciplina médica. Relaciones económicas, culturales, etc. que entrevé la fotografía médica en estas categorizaciones o también llamado eje médico-social.

- La política como un ente que regula ciertos aspectos de la medicina, las relaciones medicina y sociedad, como discurso de poder. La ciencia como un discurso de liberalización o confrontación frente a otros grupos sociales, etc. Todas estas temáticas pueden encontrarse en un análisis político de la fotografía médica.

- La estética y la técnica lo fusionaremos como un análisis único de interpretación del formato de la fotografía médica. Ya que queremos ampliar el concepto estético como la asociación a la belleza que se hace tradicionalmente y proponerlo también como un marco que comprende la coyuntura o la espontaneidad de las técnicas de los sujetos comprometidos en la fabricación del documento. Además, integrar la construcción que el investigador 
hace para comprender el registro, clasificando símbolos dentro de la iconografía médica y los objetos e imágenes que va producir esta fotografía. Los registros documentales de la imagen, muchas veces nos enseñan a entender estas habilidades, tanto en la fotografía como en la medicina. A esto llamaremos eje médico estético.

- Por último, entender lo institucional como las intenciones o determinaciones organizacionales que se quiere plasmar en la fotografía médica. El sentido de pertenencia corporativo que entrega el documento a la sociedad o al ente imaginario que lo recibe y lo percibe visualmente. La institución como la estructura que manda construir el documento visual para entregar un mensaje o cumplir con ciertos objetivos (propaganda, influencia social, filantropía, salud, etc.).

Entonces, estas directrices o ejes de análisis las denominaremos: eje médico-social; eje médico-político; eje médico estético y eje médicoinstitucional. No sabemos si esto puede ser considerado solamente para la fotografía patrimonial médica, lo importante es saber si nos atrevemos a entender la fotografía de muchas dimensiones para poder sustentar así nuevas formas de construir la historia de la medicina.

\section{Figura I}

- Eje médico-social: orate, en griego, significa visionario; en este caso se aplicaría como 'el que ve visiones' (Diccionario de ciencias médicas, 1824 Facultativos de la corte. Diccionario de ciencias médicas, tomo XXIII. Madrid: Imprenta Real. P.3 La Casa de Orates se creó en Santiago de Chile en 1852 con el nombre de Casa de Orates de Nuestra Señora de los Ángeles (Costa, 1980, p.559). Posteriormente recibe el nombre de Manicomio Nacional y en el siglo XX se transforma en el Instituto Hospital Psiquiátrico.

- Eje médico-estético: este registro nos muestra mujeres pobres, mestizas y algunas con fuertes rasgos indígenas. Algunas sonríen, otras eluden la mirada fotográfica, pareciera que fueron puestas allí sin su consentimiento, por eso el desgano y la apatía. El cabello sin peinar, de algunas, es quizás el símbolo de su abandono. El código tácito de embellecerse para una fotografía aquí está doblemente ausente, ni el fotógrafo, ni las modelos-pacientes, reparan en modificar su aspecto para aparecer 'mejor'. No importa, están locas. Nadie se preocupa de su belleza pública, su higiénica belleza. Están abandonadas.

- Eje médico-social: al analizar esta fotografía, resulta imposible no especular respecto a las razones que las llevaron a estar recluidas 
en una institución psiquiátrica, más allá del posible diagnóstico clínico. Es un hecho evidente que muchas veces estos espacios cumplieron funciones de castigo para mujeres que se salían de las normas sociales, por ello sería importante considerar el número, sexo y diagnósticos de los pacientes para comprender todas las funciones que estos espacios cumplieron. Las melancolías eróticas, la locura religiosa y alcohólica (Echeñique Gandarillas, 1926, p.67) pueden interpretarse dentro de un contexto social que reprimía la sexualidad o la intelectualidad de las mujeres. Otro punto de análisis resulta del estudio de los oficios que ejercían estas mujeres, tales como lavanderas, costureras y dueñas de casa, los que se podrían relacionar a fuerte explotación física y psíquica que condicionaban su salud mental. La cotidianeidad de los espacios hogareños muchas veces ocultaba diferentes grados de miseria y violencia conyugal en sus vidas.

- Eje médico-institucional: el grado de profesionalidad o especialización del cuerpo médico que atendía el establecimiento podría darnos luces respecto a las funciones que cumplía éste.

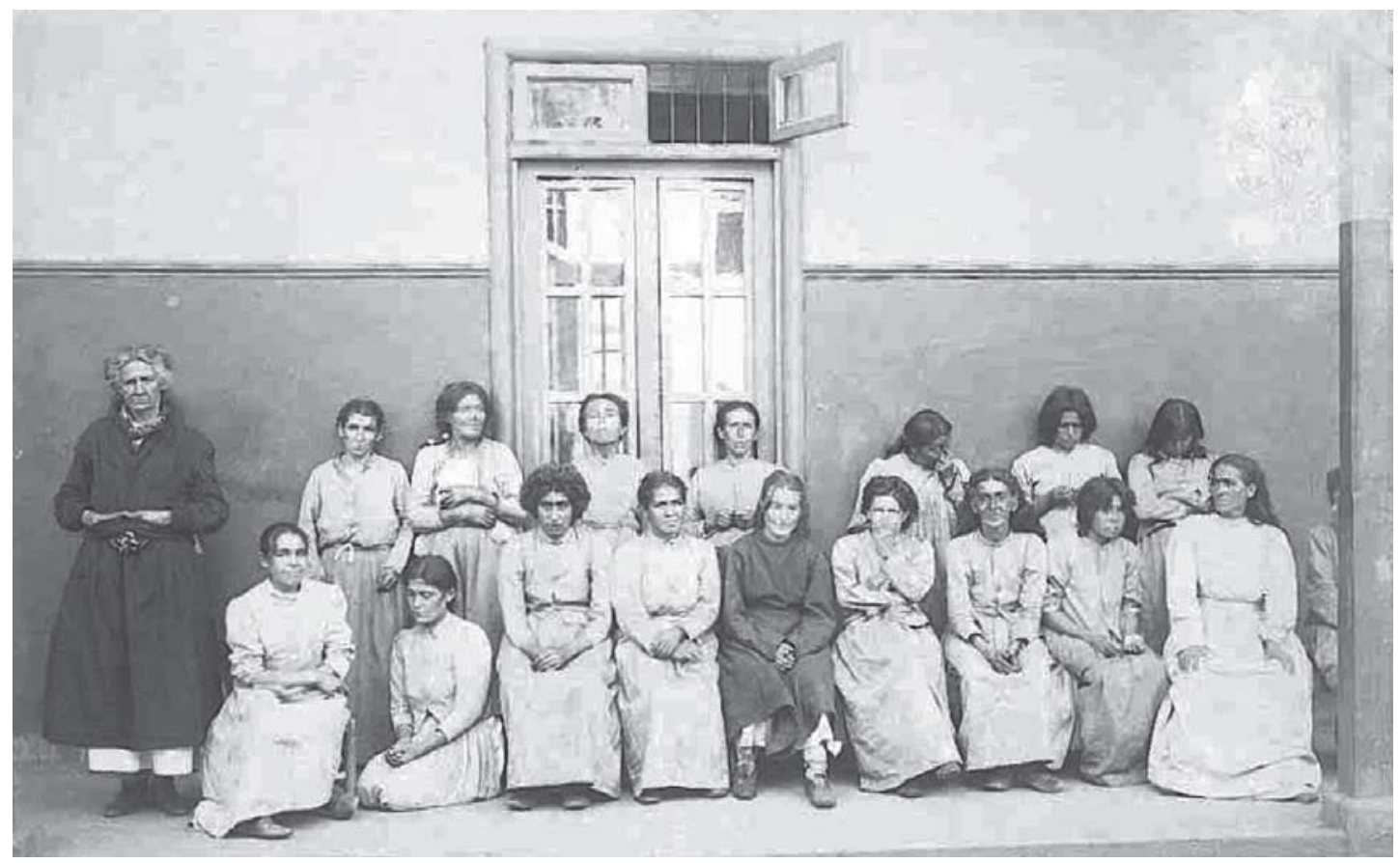

Figura 1

Casa de Orates. Sección Mujeres

Año: comienzos del siglo XX, aproximadamente 1900-1930.

Autor: Martínez.

Técnica: albúmina. (técnica que se basa en cubrir un papel con albúmina, que es una proteína del huevo que se sensibiliza a la luz y fija la imagen en una superficie).

Archivo: Museo Enrique Laval, Colección. Álbum de la Casa de Orates.

Contexto institucional: visita de autoridades. 
Muchas instituciones hospitalarias, desde sus orígenes, sirvieron como depósitos de marginalidad social donde se concentraban los sujetos no deseados (Dellacasa, 2000, p.44). Con él entenderemos el paradigma psiquiátrico que soportó su origen, desarrollo y etapas. Es lícito preguntarse por el origen de la fotografía. ¿Era para una memoria del establecimiento o para estudio clínico? ¿Si fueran mujeres de elite, las expondrían a la fotografía? ¿O solamente se expone la mirada enferma de la pobreza y marginalidad? Nosotros creemos que existe una profilaxis social, una especie de mirada higiénica que justifica la segregación social, pero desde otro punto de vista, el científico. ¿La fotografía médica tiene una asepsia social? ¿De espacios, de orden?

\section{Figura 2}

- Eje médico-social: se observa que la mayoría de los hombres tienen un aspecto de marginalidad, su ropa nos indica su origen popular. Pobreza y mestizaje se repite en la fotografía. Los diagnósticos psiquiátricos no nos son conocidos. Sin embargo, es importante para su análisis entender la relación estrecha entre marginalidad y algunas etiologías psiquiátricas, es decir, locura sifilítica o alcohólica, incluso la asociación de mestizaje a locura hereditaria y degeneración que hegemonizaron la psiquiatría y el racismo científico de fines del siglo XIX. Estos diagnósticos no son atribuidos o especulativos, son los que más se repiten entre 18901930 en las cuentas de la Casa de Orates de Santiago de Chile (Movimiento..., 1904, p.22).

- Eje médico-estético: la mayoría de los individuos retratados tienen un aspecto de peones 'gañanes', especie de trabajador nómada rural que habitó los campos chilenos gran parte del siglo XIX hasta principios del siglo XX y que sufrió un desplazamiento social con los procesos de industrialización. Hay otros sujetos que tienen gorras militares, lo que podría datar la fotografía cercana a un conflicto bélico. Cobra entonces sentido la posibilidad que se trate de veteranos de la Guerra del Pacífico o del Salitre en 1879 o la Revolución de 1891. También podría señalar una donación del ejército a estas instituciones de salud con pertrechos dados de baja. Considérese aquí que un edificio destinado al nuevo Manicomio de Santiago de Chile, por esta época, fue expropiado por el Ministerio de Guerra y luego entregado a la caballería del ejército.

- Eje médico-político: en el extremo derecho de la imagen se identifica a un joven doctor, Joaquín Luco Arraigada, nacido en 1870, y a un grupo de guardianes que le acompañan, configurando un espacio de poder dentro de las estructuras jerárquicas de la fotografía. 
- Eje médico-social: desde la perspectiva social, podemos inferir que la presencia de trabajadores rurales en un espacio psiquiátrico podría implicar el fuerte impacto del proceso de industrialización que trajo como consecuencia un incremento de la locura alcohólica, producto del aumento del consumo del alcohol destilado en las dietas de los peones, quienes acostumbraban a beber alcohol fermentado de un muy inferior grado etílico (Huertas García-Alejo, 1987, p.61). Por otra parte, un conflicto bélico también implica una población dañada, no solamente en términos físicos, sino también en términos mentales.

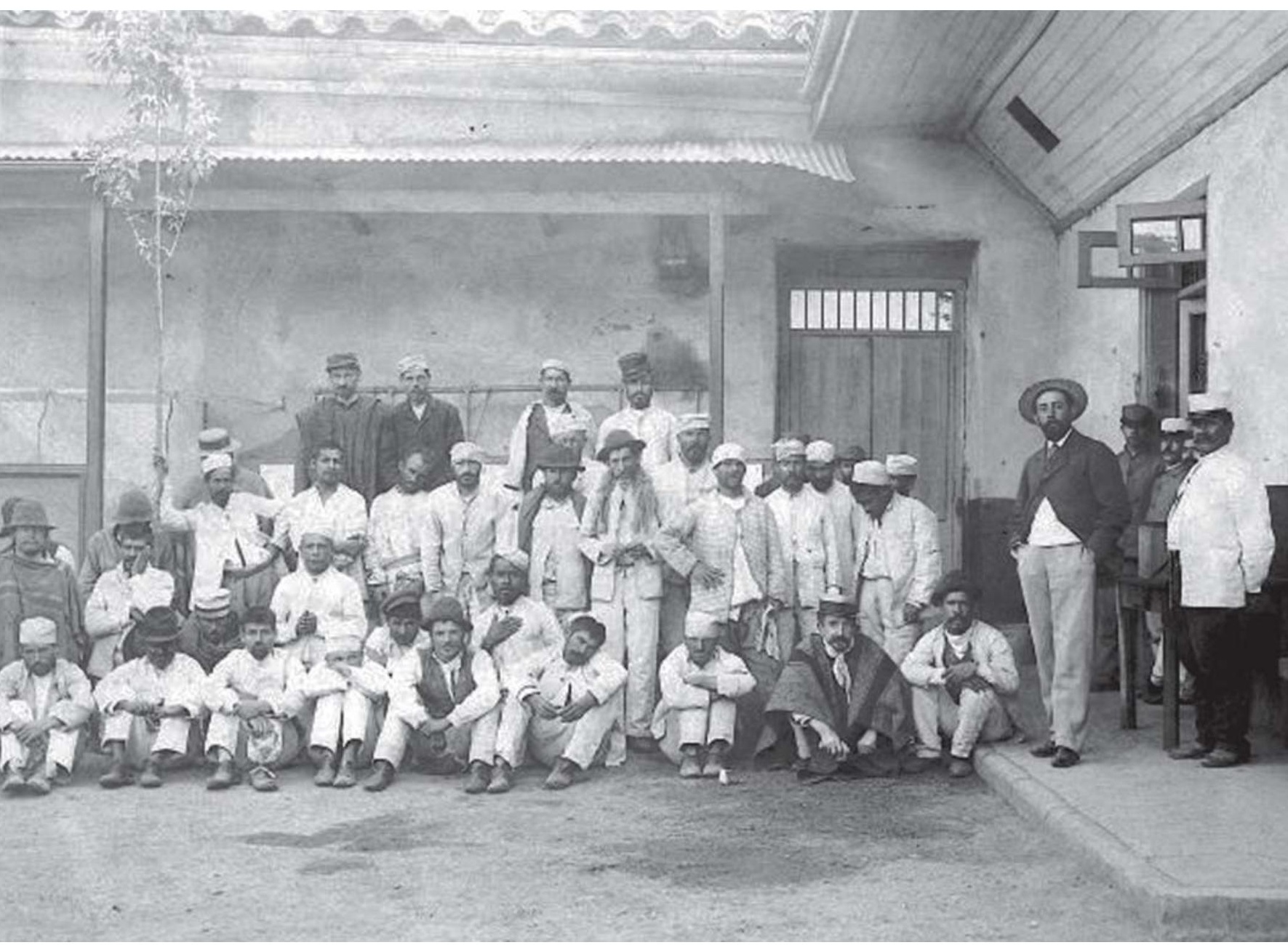

Figura 2

Casa de Orates. Sección Hombres.

Año: comienzos del siglo XX, aproximadamente 1900-1930.

Autor: anónimo.

Técnica: albúmina

Archivo: Museo Enrique Laval, Colección Álbum de la Casa de Orates.

Contexto institucional: visita de autoridades 


\section{Figura 3}

- Eje médico-social: las preguntas iniciales son: ¿Qué hace un archivo de reos de mediados del siglo XIX en un espacio hospitalario? ¿Fue un hecho fortuito o hay una intención biológica y médica? Al lado de cada fotografía hay una serie de descripciones criminales y físicas de los prisioneros. Datos como el delito que cometió, el lugar geográfico y la pena o condena. En términos físicos, medidas como altura, peso y sobre todo la descripción anatómica de ciertas características vinculadas a enfermedades: calvicie, cicatriz, catarata, etc. ¿Hay una descripción biométrica aplicada a la delincuencia? (Sekula, 2003a., p. 134).

¿Puede haber sido la fotografía médica, el primer referente para la naciente industria de la vigilancia o identificación? (Sekula, 2003, p.134).

- Eje médico-político: a fines de la industrialización, las problemáticas sociales creadas por ésta son falta de vivienda, epidemias, marginalidad social, delincuencia, etc. Son problemas que las elites tradicionales no pueden resolver, su represión y control (manipulación religiosa) ya no funcionan en estos nuevos espacios urbanos

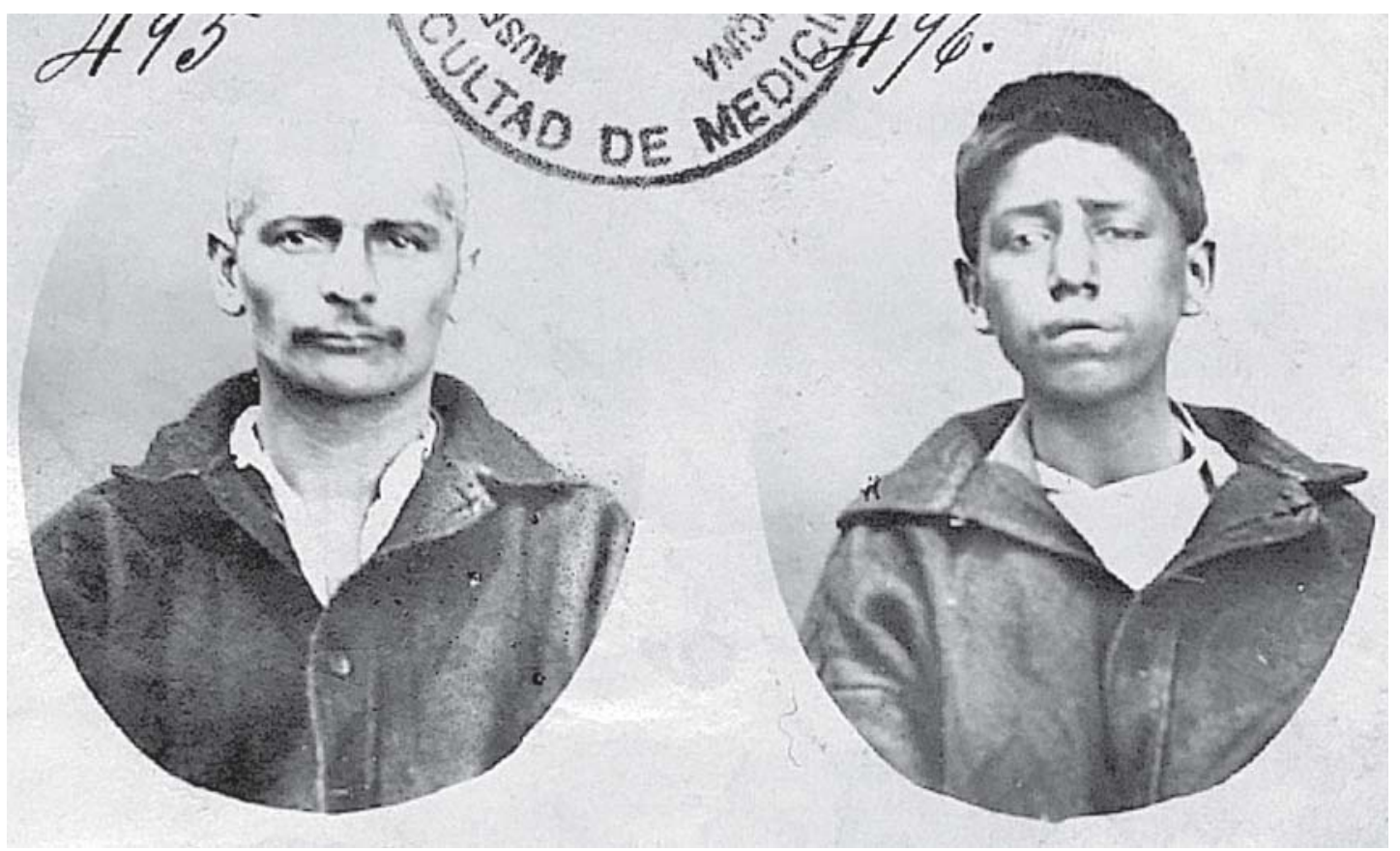

Figura 3

Retrato de prisionero de la cárcel de la ciudad de Talca. N. de fotografías 495-496.

Año: 1869-1874.

Autor: anónimo.

Técnica: albúmina

Archivo: Museo Enrique Laval, Colección. Álbum de reos de Talca, 1869-1874.

Contexto institucional: catastro. 
que poseen una nueva estructura mental. Por lo tanto, hay que planificar nuevas formas de técnicas de inspección que delimiten a las enfermedades y a los individuos que habitan la urbe y que se van a manifestar en el control de la ciudad y el cuerpo de los individuos que la componen. ¿Qué grupo intelectual o político presentó la solución a estas dificultades sociales? La medicina sería la que entregó la solución. ¿Será esta fotografía la materialización de esta nueva forma de control? - una medicina rectora, fiscalizadora que interviene otros espacios de las normas (judicial, por ejemplo) ¿Esta fotografía concreta el nacimiento de la medicina legal chilena? ¿Es el sueño de los higienistas y la conquista de lo público (higiene pública, ciudad) a lo privado (higiene racial, sexual, mental, cuerpo)?

\section{Figura 4}

- Eje médico-social: descripción pormenorizada del prisionero con sus características físicas. Substancialmente sus cataratas en sus ojos y la enfermedad llamada 'cotudo' que puede haber sido bocio. Esto arroja información sobre ciertas enfermedades de la población, la falta de ciertas vitaminas en su dieta, si lo relacionamos de donde viene territorialmente podemos encontrar las huellas de una enfermedad local. También podemos vincularlo a teorías médico-degeneracionistas de la época. Puede ser que ya estén las teorías de los estigmas de Lombrosio en Chile o de la degeneración de Magnam y Morgan (Huertas García-Alejo, 1987, p.105), la biologización de la delincuencia o la biometría fotográfica de criminales de Alfonso Bertillón, pudiendo ser la ideología de fondo que opere en estos espacios médicos.

- Eje médico-político: también puede ser que estas fotografías no tengan ninguna intención médica o antropométrica, sino un simple archivo de reos de tipo policíaco, donde se describen sus características para su futura identificación. Pero aquí hay algo interesante, el uso que se le está dando a la fotografía a mediados del siglo XIX, como un dispositivo de poder público. Este puede ser un inicio de un panóptico visual que busca el control de la delincuencia, con nuevas técnicas; la anormalidad es un rasgo constitutivo que 'identifica' a este nuevo 'monstruo moderno' (el delincuente). Su cuerpo anormal denuncia su sospecha en un posible delito. Lo especifica de la masa, lo desnuda a través del documento fotográfico. La fotografía de delincuente está analizada desde formas médicas que posteriormente en el siglo XX serán los nuevos sistemas de vigilancia policial. Junto a la fotografía del inmigrante (pasaporte) son los nuevos sospechosos, de nuevas formas de peligro. Rompen la moral, los límites de la naturaleza, de las 


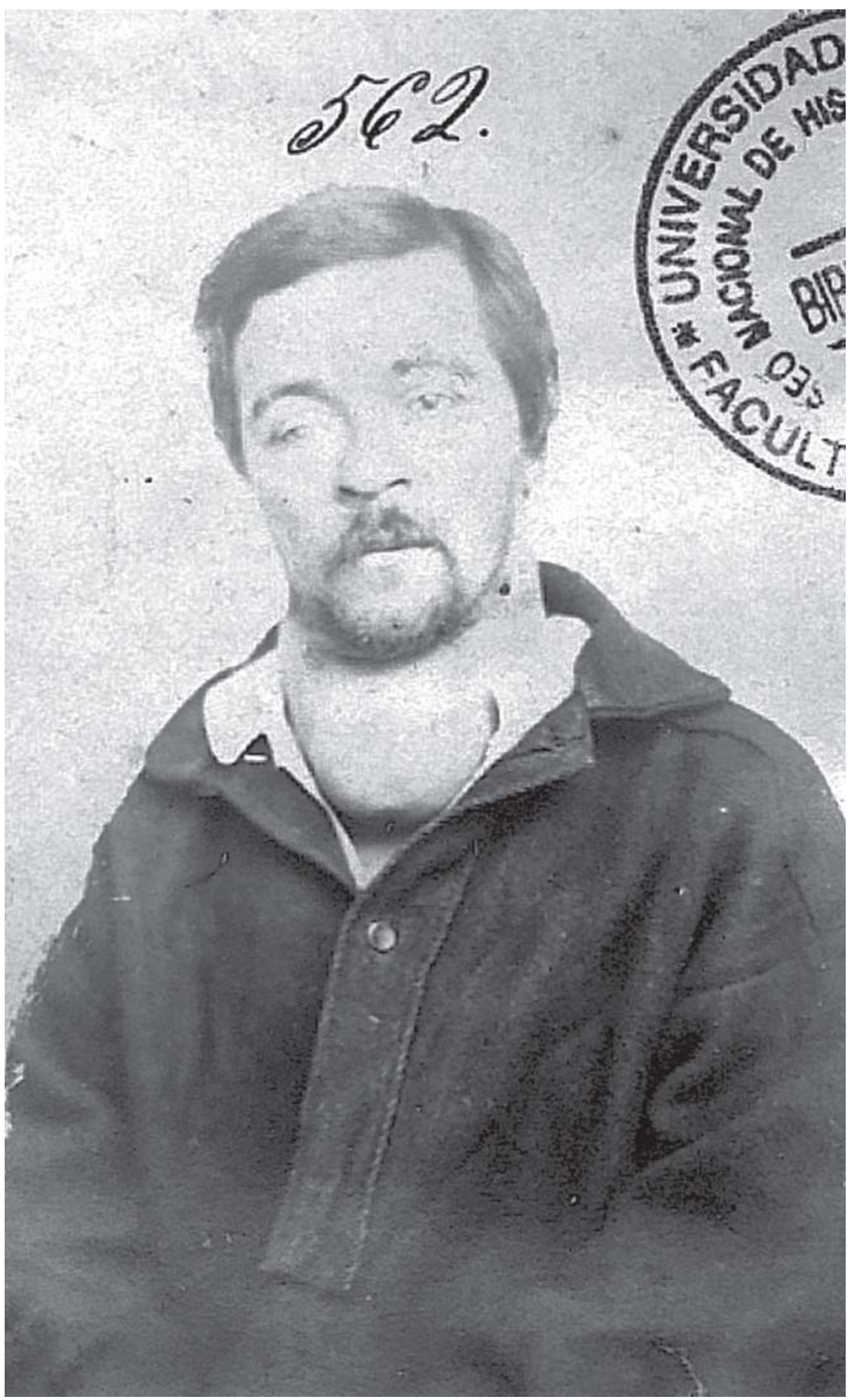

Figura 4

Retrato de prisionero de la cárcel de la ciudad de Talca. N. de fotografía 562. Año: 1869-1874.

Autor: anónimo.

Técnica: albúmina.

Archivo: Museo Enrique Laval, Colección. Álbum de reos de Talca, 1869-1874. Contexto institucional: catastro. 
fronteras, de los muros o cordones sanitarios y nacionales, etc. Roban las riquezas nacionales o privadas, un nuevo 'bárbaro' que hay que identificar y la biología, la medicina y la fotografía van a participar de este nuevo sistema de reconocimiento del 'anormal' que fue el delincuente. En el siglo XXI, será la fotografía del delincuente-inmigrante-terrorista la nueva imagen a analizar.

\section{Figuras 5 y 6}

- Eje médico-social: el paciente tiene blefarospasmo bilateral histérico, una especie de 'guiño' o movimiento continuo en el ojo, que no le permite ver. Es un policía o carabinero chileno que según el estudio sufrió este tipo de ceguera producto de un fuerte trauma que vivió. Es importante en la historia de la medicina porque la histeria había estado asociada a las mujeres, desde los griegos. Era
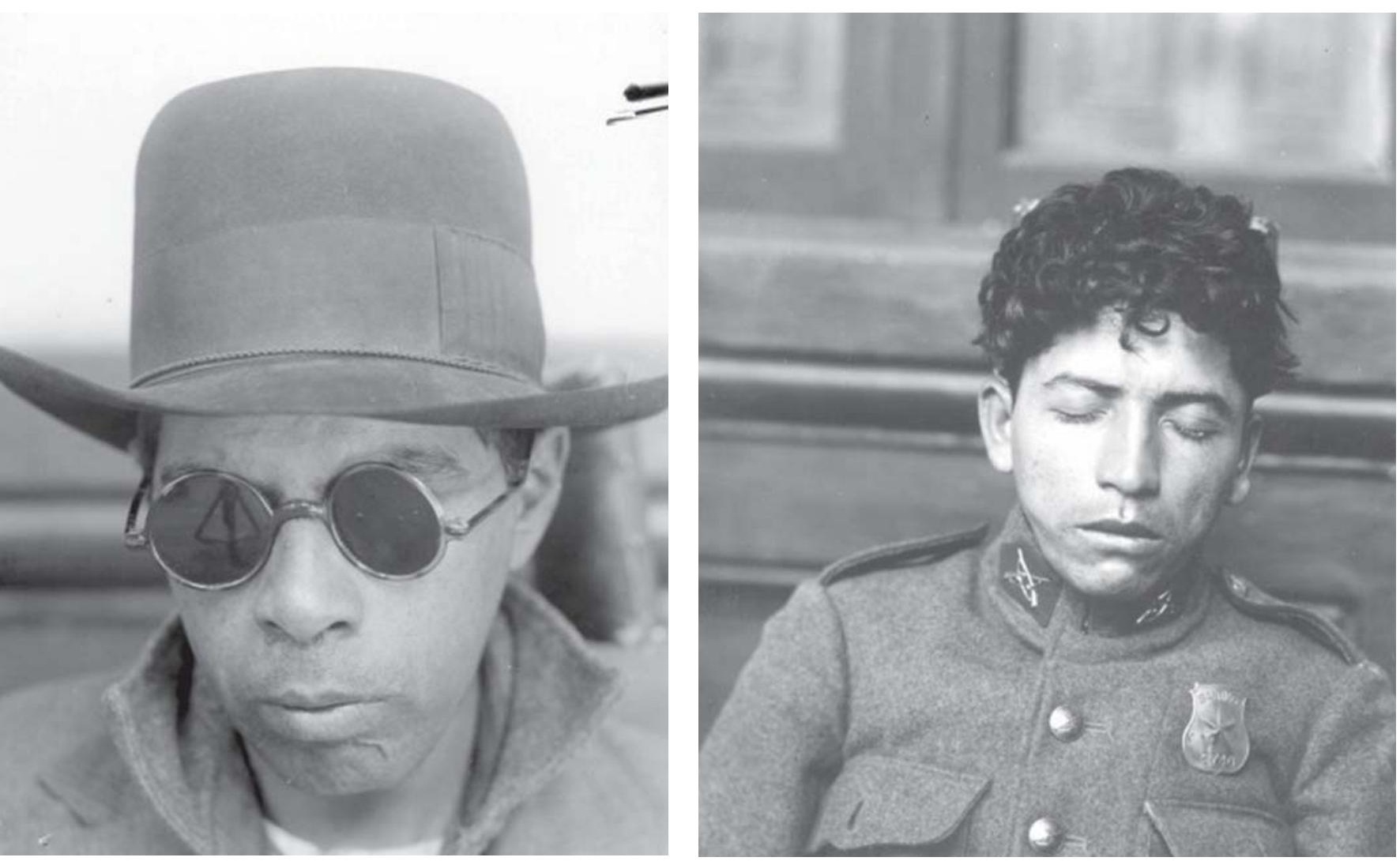

Figuras 5 y 6

Retrato de paciente del El Salvador, hospital de fines del siglo XIX, construido como el primer lazareto en Chile.

Año: 1931.

Autor: anónimo.

Técnica: desconocida.

Archivo: Museo Enrique Laval, Colección. Tesis médica.

Contexto institucional: tesis de oftalmología. Doctor Raimundo Charlín. 
considerada producto de una deformación al útero, por lo tanto, encontrarla en esta fotografía en un hombre va marcando un cambio de criterio médico en el diagnóstico de la enfermedad.

- Eje médico-estético: hay observaciones médicas sobre el paciente en la fotografía, su actitud corporal; nótese la completa indiferencia del enfermo.

- Eje médico-político: además es importante considerar cómo encontramos un individuo asociado a la autoridad en este espacio hospitalario. Aquí la asepsia social está abandonada y se nos permite observar de otra forma a la autoridad, vulnerable y enferma. Igual hay que considerar que es un carabinero de poco rango y mestizo. Sería diferente ver a un general enfermo en la imagen.

\section{Figura 7}

- Eje médico-social: este individuo tiene un diagnóstico de ambliopía que es un oscurecimiento de la visión por sensibilidad imperfecta de la retina y sin lesión orgánica del ojo. Lo interesante de la fotografía es que hay una nota que resalta que el paciente está 'simulando'. Esto implica que las redes o estrategias de sobrevivencia de estos sujetos operaban en estos espacios. Es posible que lo hicieran para cobrar dinero en el Seguro Obrero y así tener acceso a beneficios sociales de salud.

- Eje médico-estético: aquí hay un doble montaje, la fotografía retratando al sujeto, individualizando su engaño o posible enfermedad,

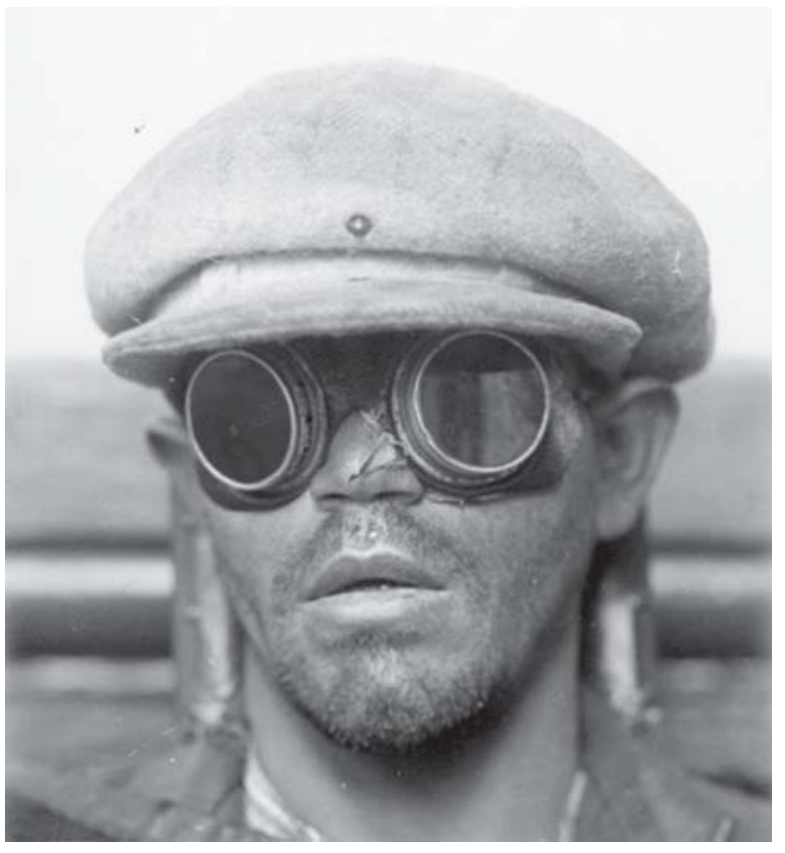

Figura 7

Retrato de paciente del El Salvador, hospital de fines del siglo XIX, construido como el primer lazareto en Chile.

Año: 1931.

Autor: anónimo. Técnica: desconocida Archivo: Museo Enrique Laval, Colección. Tesis médica.

Contexto institucional: tesis de oftalmología.

Doctor Raimundo

Charlín. 
y hay otro montaje, el del propio paciente, el cual enfrenta a este lente y al médico que pretende develar su representación o imagen falsa de enfermedad. Es importante plantear que el médico cumple nuevamente un rol fiscalizador, el descubrimiento de una simulación de ceguera para proteger al Estado de no pagar seguros sociales a individuos 'maleantes'. La fotografía es la prótesis que corrige a estos 'charlatanes', 'embaucadores', que enfrentan a esta doble mirada rectora: la médica y la fotográfica. Hay una nueva mirada anátomopatóloga que observa, ya no la anormalidad física sino la más invisible de todas, la psíquica y la moral corrompida. Por lo tanto, se necesita de nuevos objetos técnicos para analizarlos. Esta fotografía médica es una mirada post-Morgagni o post-Charcot, donde la anormalidad, lo deforme, lo fenómeno, no busca la enfermedad del cuerpo sino el delito, la falta del individuo, del delincuente, conceptosclaves para el nuevo orden industrial y la nueva cultura de las clases dominantes y factores que también tienen que haber influenciado a la medicina de tiempos de la industrialización.

\section{Conclusiones}

Este artículo ha pretendido ser un análisis teórico sobre la incorporación de la imagen médica en los estudios de la historia de la medicina. Un referente metodológico que permita trabajar el archivo visual como un elemento nuevo, que nos posibilita acceder a nuevas construcciones metodológicas de nuestras fuentes históricas. Es un trabajo exploratorio, experimental, que busca ampliar los fundamentos de nuestras propuestas. La gran cantidad de información que nos entregan estos archivos visuales debe ser estudiada como parte de nuestras investigaciones en los estudios de la historia de la medicina. Los espacios que nos traspasa la imagen médica van más allá de una especie de escenografía visual específica, neutral, limpia y aséptica, que no encierra ningún contexto temporal o ideológico, sino que va más allá de los propios intereses médicos que sostiene, convirtiéndose en un material tangible de construcción sólida para todos los aspectos que contiene la historia de la medicina. La integración de fotografías médicas, grabados de atlas, retratos de médicos, planos de hospitales, pacientes, aparatos, instrumentos, etc., son fuentes de imágenes que sirven para elaborar una anatomía de todo el discurso visual que tiene esta fotografía médica y todo el potencial que ella posee como archivo histórico. La gran cantidad de publicaciones ilustradas que conservan nuestros museos y bibliotecas patrimoniales en nuestra América deben ser una fuente constante de consulta teórica para nuestras publicaciones. La realidad médico-social que encierran estos fragmentos visuales van a desarrollar nuevos conductos teóricos que abran este campo de investigación. 
Por último, nos encontramos con un fenómeno interesante para la historia de la medicina y su relación con la fotografía o la imagen en general. La industrialización de fines del siglo XIX y comienzos del XX, de donde pertenecen cronológicamente la mayor cantidad de fotografía analizadas, hará emerger o surgir en estos registros a un actor o a un sujeto histórico que tradicionalmente había estado segregado en la pintura o fotografía de retratos, que solamente estaba reservada para los retratos familiares aristocráticos y la emergente burguesía industrial. En estos retratos médicos, como una especie de visión fantasmal, hay una 'reaparición del sujeto', del cotidiano, del común, del popular. Se podría decir que aunque la industrialización fue un proceso de exclusión en el pasado de estos grupos sociales, hay una contradicción que quedó plasmada en la fotografía médica, la aparición del mundo popular como mano de obra, como paciente, como delincuente, pero instalándose en espacios sociales y visuales que históricamente les habían estado prohibidos y es aquí donde los volvemos a encontrar, en los archivos fotográficos médicos, como una huella social que hay que seguir en nuestras futuras investigaciones.

Por buenas razones los antiguos magos expresaban sus profecías en imágenes y no por escritos. ¿Pues quién se atreve a decir la verdad desnuda a un rey? Yo, mejor no, no vaya a ser mi recompensa el cadalso. Ningún mago, astrólogo o quiromántico debería decir la verdad desnuda a su soberano. Debería usar imágenes, alegorías, figuras o expresiones maravillosas, $\mathrm{u}$ otros caminos ocultos o indirectos. (Paracelso, 1528, citado en Pachter, 1955, p.65)

\section{BIBLIOGRAFÍA}

Bourdieu, Pierre 1998

Burke, Peter

2000

Costa-Casareto, Claudio 1980

Dellacasa, Carlos 2000

Duby, George 1999

Echeñique Gandarillas, Francisco 1926
La fotografía, un arte intermedio.

México D.F.: Nueva Imagen.

Visto y no visto: el uso de la imagen como documento histórico.

Barcelona: Crítica.

Ideario psiquiátrico del medico de la Casa de Locos de Santiago en 1862. Revista Médica de Chile, Santiago, v.108, p.559-597.

Ecos del tratamiento de la locura en Buenos Aires a principios del siglo XX. In: Ríos, Julio C. et al. (Comp.). Psiquiatría, psicología y psicoanálisis: historia y memoria. Buenos Aires: Polemos. p.40-48.

Año 1000, año 2000: la huella de nuestros miedos.

Barcelona: Crítica.

Memoria de la Casa de Orates. Santiago:

Soc. Imprenta y Litografia Universo.

Facultativos de la corte. Diccionario de ciencias médicas, tomo XXIII.

Madrid: Imprenta Real. 
Foucault, Michael Los anormales.

2000

Ciudad de México: Fondo de Cultura Económica.

Foucault, Michael Vigilar y castigar.

1985

Barcelona: Editorial Siglo XXI.

Huertas García-Alejo,

Rafael

1987

Locura y degeneración: psiquiatría y sociedad en el positivismo francés.

Madrid: Consejo Superior de Investigaciones Científicas/Centro de Estudios Históricos.

Movimiento...

Movimiento de la Casa de Orates1903.

1904

Santiago: Imprenta Universitaria.

Müller, Andreas

1996

La dimensión fotográfica: estrategias contemporáneas en el arte.

Papel Alpha, Salamanca, n.1, p.3-15.

Nungesser, Michael 2004

Hugo Brehme, un fotógrafo alemán en México.

Humboldt, n.141, p.9-10.

Olivares, Rosa dic. 1996

El retrato como medio de conocimiento.

Lápiz, Madrid, n.127, p.31-39.

Pachter, Henry

Paracelso: de la magia a la ciencia.

1955

México: Grijalbo

Ruiz, María José' 1993

El cuerpo limpio: análisis de las prácticas higiénicas en la España del mundo moderno. Málaga: Universidad de Málaga.

Sekula, Allan

El cuerpo y el archivo. In: Picazo, Gloria; Ribalta, Jorge (Ed.). Indiferencia 2003 y singularidad. Barcelona: Gustavo Gili. p.133-200.

Sontag, Susan

1981

Sobre la fotografía. Madrid: Edhasa.

FILME

Le Familistère: une cité radieuse au 19.eme siécle. Realización de Catherine Adda. Issy-les-

Molineaux: Arte France. Film documental (28 min). 1996. 